\title{
Evolution of the selfing syndrome in Ipomoea
}

\section{Tanya M. Duncan and Mark D. Rausher*}

Department of Biology, Duke University, Durham, NC, USA

\section{Edited by:}

Jill C. Preston, University of

Vermont, USA

Reviewed by:

Philip W. Becraft, lowa State

University, USA

David Smyth, Monash University,

Australia

*Correspondence:

Mark D. Rausher, Department of Biology, Duke University, 124

Science Drive, Durham, NC

27708, USA

e-mail:mrausher@duke.edu
Plants that are highly selfing typically exhibit a suite of morphological traits termed a "selfing syndrome," including reduced corollas and reproductive structures, loss of corolla pigmentation, little anther-stigma separation, and a lower pollen/ovule (P/O) ratio. While it is typically assumed that these changes are adaptive, few attempts have been made to determine whether they result from the operation of natural selection or genetic drift. In the southeastern United States, Ipomoea lacunosa has evolved a typical selfing syndrome compared to its close relative, Ipomoea cordatotriloba. Microsatellite markers confirmed that selfing rates are substantially higher in I. lacunosa. Furthermore, using a standard $\mathrm{Q}_{S T}-\mathrm{F}_{\mathrm{ST}}$ comparison, we evaluated the relative importance of selection and drift in the evolution of selfing syndrome traits in I. lacunosa. The analysis demonstrated that natural selection is responsible for the evolution of reduced corolla size, anther-stigma distance, and style length in this species. By contrast, leaf characteristics unrelated to selfing were found to have diverged largely by genetic drift. Our study provides one of the first confirmations that natural selection drives the evolution of selfing-syndrome traits.

Keywords: Ipomoea lacunosa, Ipomoea cordatotriloba, selfing syndrome, natural selection, genetic drift

\section{INTRODUCTION}

The evolutionary transition from outbreeding to selfing is one of the most common changes in angiosperms, with an estimated $20 \%$ of all flowering plants having evolved autogamy as the predominant mode of reproduction (Barrett, 2002). Autogamous plants are typically characterized by a "selfing syndrome," which consists of having small, scentless, nectarless, and often white flowers, reduced anther-stigma distance, and a decreased pollen/ovule (P/O) ratio (Ornduff, 1969; Sicard and Lenhard, 2011; Kalisz et al., 2012).

Traditionally, the evolution of increased selfing has been viewed as the result of natural selection, either for reproductive assurance when pollinator availability is low or potential mates are commonly absent (Darwin, 1876; Stebbins, 1950; Baker, 1955), or because of a transmission advantage associated with selfing compared to outcrossing (Fisher, 1941; Holsinger, 1988). However, not all traits associated with the selfing syndrome necessarily contribute directly to increased selfing. In particular, selfing-syndrome characters may be divided into two categories: (1) those targeted by natural selection to increase selfing rate, and (2) those that evolved for other reasons. A likely example of a trait in the first category is anther-stigma distance. In many species, it has been shown that reducing anther-stigma distance increases autogamy and increases selfing rate in nature (Chang and Rausher, 1998; Motten and Stone, 2000; Schueller, 2004; Takebayashi et al., 2006). If selection favors increased selfing, it may operate to decrease anther-stigma distance. An example of the second category is $(\mathrm{P} / \mathrm{O})$ ratio, which is typically reduced in highly-selfing species. A reduction in $\mathrm{P} / \mathrm{O}$ by itself is not likely to increase selfing rates. If anything, it is likely to decrease selfing rates because there is less pollen for self-fertilization. It is thus unlikely to be a trait targeted by selection to increase selfing rates. However, once increased selfing has evolved, decreased $\mathrm{P} / \mathrm{O}$ ratio may be the result of selection to redirect resources to other fitness-enhancing traits because less pollen is needed for effective self-pollination (Brunet, 1992).

A number of selfing-syndrome characters may fall into either category, depending upon when they evolve relative to category 1 traits. Examples are characters that serve to attract pollinators, such as showy petals, scent, and nectar rewards. On the one hand, reduction in attractiveness may itself increase selfing rates by reducing visitation by pollinators carrying pollen from other plants. If these traits are genetically variable when selection arises for increased selfing, they may become targets of selection and hence be category 1 traits. On the other hand, if reduced attractiveness does not reduce visitation, or if there is little genetic variation in these traits when selection for increased selfing arises, these traits may not evolve in response to such selection. Subsequently, however, other forms of selection, including selection for reducing costs of production, for shortening the time involved in reproduction, or for reducing floral herbivory, may act to alter these characters [reviewed in Sicard and Lenhard (2011)].

These arguments all assume that some form of natural selection molds the suite of characters that comprise the selfing syndrome. Seldom considered is the alternative possibility that some of these characters are neutral and have evolved by genetic drift. Such change, however, is plausible. For example, once a population has become highly selfing, there is no longer a need to attract pollinators, and selection to maintain attractive traits would be relaxed. It is easy to imagine that under these circumstances, loss-of-function mutations that abolish function could accumulate to reduce pigmentation, scent, and nectar production. Similarly, it is also conceivable that drift could frequently lead to a general reduction in flower size, especially if mutations reducing flower size are more frequent than mutations that 
increase flowers size. The possible importance of genetic drift is enhanced by the fact that selfing tends to reduce genetic diversity within populations. In particular, inbreeding associated with selfing tends to increase homozygosity (Charlesworth and Wright, 2001). Excess homozygosity in turn lowers the effective population size $(\mathrm{Ne})$ and increases the effect of genetic drift in selfing plants (Pollak, 1987).

Our objective in this study was to explicitly examine whether natural selection was responsible for the evolution of selfingsyndrome characters in the annual morning glory Ipomoea lacunosa, which has diverged from the closely related Ipomoea cordatotriloba in floral morphology (Duncan, 2013, in press). Specifically, I. lacunosa has a short anther-stigma distance, small, white flowers, and a low $\mathrm{P} / \mathrm{O}$ ratio compared to I. cordatotriloba, which has a greater anther-stigma distance, larger, purple flowers, and a higher P/O ratio (Austin, 1978; McDonald et al., 2011). We first demonstrate, using microsatellite markers that selfing rate is generally substantially higher for I. lacunosa than for $I$ cordatotriloba. We then use a Qst-Fst comparison to determine whether two selfing-syndrome traits exhibit divergence that is inconsistent with the operation of genetic drift. One character is reduced anther-stigma distance, which we expected to have been favored by selection because it is a character that presumably affects selfing rate substantially. The second character we examine is flower size, a presumably attractive trait, which is reduced in $I$. lacunosa. For this trait, we had no a priori expectation about the involvement of natural selection.

\section{MATERIALS AND METHODS STUDY SYSTEM}

I. lacunosa and I. cordatotriloba are noxious weeds that are indigenous to the southeastern United States (Jones and Deonier, 1965). The two plants have different floral morphologies, with I. lacunosa typically having small white flowers, and I. cordatotriloba normally having larger, purple flowers (Abel and Austin, 1981). A recent analysis of shared genetic variation suggests that I. lacunosa and I. cordatotriloba are exchanging genetic material because they are genetically indistinguishable at neutral markers (Duncan, 2013, in press). Reflecting this genetic similarity, the two species can cross and produce viable offspring (Abel and Austin, 1981; Duncan, 2013, in press). In North Carolina (NC) and South Carolina (SC) the ranges of the two species overlap, with I. lacunosa growing along the coast as well as in the central area of the two states, while $I$. cordatotriloba is found predominately along the coast (Duncan, 2013, in press). In NC and SC the plants germinate in late May and begin to flower in August or early September. Flowering ceases sometime in mid to late fall and plants die at the first hard frost. Plants of each taxon are self-compatible; however, I. cordatotriloba has been described as having a mixed mating system (selfing and outcrossing), while I. lacunosa is thought to reproduce largely by self-pollination (McDonald et al., 2011).

\section{Geographic survey and floral measurements}

In August and September of 2010, we conducted a census of 7 populations of I. cordatotriloba and five populations of I. lacunosa in NC and SC. In each population we measured morphological traits on an average of 12 and 20 individuals, respectively, for the two species. During the survey morphological measurements of flower width, flower length, flower width-length ratio, antherstigma separation, style length, leaf length, leaf width, and leaf width-length ratio (Figure 1). Anther-stigma distance was quantified as 0 if all anthers touched the stigma, 0.5 if at least one, but no more than 4, touched the stigma, and as 1 if no anthers touched the stigma. Correlations among traits within a population were calculated using $\mathrm{JMP}^{\circledR}$, Version 9, SAS Institute Inc., Cary, NC, 1989-2007. The average correlation coefficient for all populations was then calculated.

\section{Microsatellite scoring}

During the survey, leaf tissue was collected for genotyping microsatellite markers from each measured plant. DNA was extracted using a CTAB protocol (Doyle and Doyle, 1981). We used primers that had been developed for I. trifidia but were also reported to amplify microsatellite regions in I. lacunosa (Hu et al., 2004). Out of the eight microsatellites reported to amplify in $I$. lacunosa, we found that only four amplified and contained sufficient variability to distinguish among the study taxa. Each of the four microsatellite markers was amplified with Hex or Fam fluorescently labeled primers, using KAPA taq (Kapa Biosystems, Woburn, Massachusetts, USA), and fragment analysis was conducted on a ABI $3730 \times 1$ DNA Analyzer. Each marker was visually scored using the software GENEMARKER (SoftGenetics, 2005, State College, Pennsylvania, USA).

\section{ESTIMATING SELFING RATES}

We did not estimate selfing rates directly; instead, selfing rates were estimated indirectly from neutral markers (microsatellites). In particular, our sampling of populations and individuals

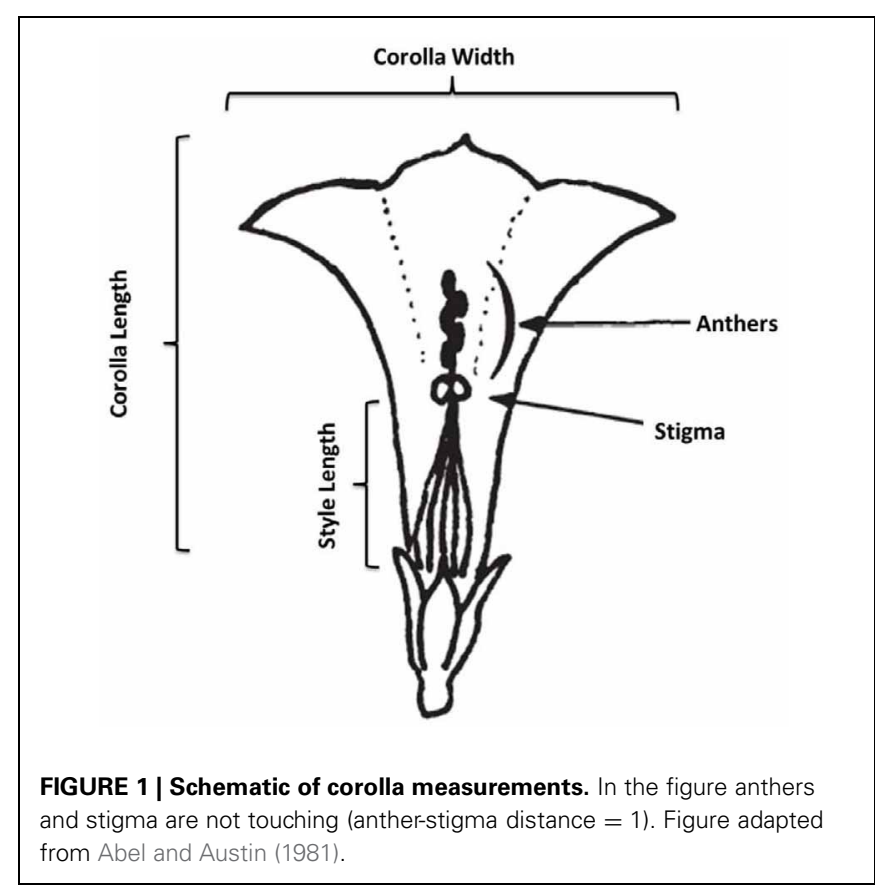


allowed us to estimate selfing rates from observed heterozygosity, $H$. Selfing rate is related the inbreeding coefficient, $F$, by

$$
s=2 F /(1+F)
$$

(Hartl and Clark, 1997). In turn, the inbreeding coefficient is related to heterozygosity by

$$
F=\left(H_{0}-H\right) / H_{0}
$$

where $H_{0}$ is the expected heterozygosity based on allele frequencies and random mating (Hartl and Clark, 1997). Combining these two equations yields the relationship between selfing rate and heterozygosity:

$$
s=2\left(H_{0}-H\right) /\left(2 H_{0}-H\right)
$$

Estimation of selfing rates for individual populations were based on four microsatellite loci sampled from 97 I. cordatotriloba individuals from 7 populations and 110 I. lacunosa individuals from 8 populations (Duncan, 2013, in press). Observed and expected heterozygosity were calculated using the program Arlequin 3.5 (Excoffier and Lischer, 2010).

\section{RELATIONSHIP BETWEEN MORPHOLOGICAL VARIABLES AND SELFING RATE IN I. cordatotriloba}

The statistical significance of variation in morphological characters among $I$. cordatotriloba populations was assessed using a one-way analysis of variance as implemented by the GLM procedure in SAS (SAS Institute Inc., Cary, NC, 1989-2007). The relationship between population means for selfing rate and morphological variables and their squares was assessed by regression analysis using a backward elimination procedure implemented by the REG procedure in SAS. The critical value for keeping a variable in the model was set to $p=0.05$.

\section{MORPHOLOGICAL TRAIT DIVERGENCE}

To determine whether trait divergence between the two species is larger than expected under neutrality, we used a modified F $_{\text {ST }}-Q_{\text {ST }}$ approach (Whitlock and Gilbert, 2012). The standard $\mathrm{F}_{\mathrm{ST}}-\mathrm{Q}_{\mathrm{ST}}$ approach compares populations at a single spatial level (e.g., Leinonen et al., 2008; Whitlock, 2008). However, in our analysis populations are nested within species and we are primarily concerned with examining divergence between species. There are thus two hierarchical "spatial" levels.

For each morphological trait measured, we calculated the summary statistic $Q_{\mathrm{CT}}$ using the method developed by Whitlock and Gilbert (Whitlock and Gilbert, 2012). Q QT describes the magnitude of variation for a morphological trait between I. lacunosa and $I$. cordatotriloba. Under the assumption that trait divergence is due to genetic drift, the expected value of $Q_{\mathrm{CT}}$ is

$$
Q_{C T}=V_{C} /\left(V_{C}+V_{P}+2 V_{I}\right)=F_{C T}
$$

where $V_{C}, V_{P}$, and $V_{I}$ are the components of genetic variance among species, among populations, and among individuals within populations, respectively (Whitlock and Gilbert, 2012) and $F_{\mathrm{CT}}$ is the between-species $F$-statistic for the microsatellite loci.

To test whether natural selection contributed to trait divergence between the two species, we tested whether the null hypothesis of no selection, corresponding to the above equation, could be rejected in favor of the hypothesis that $Q_{\mathrm{CT}}>F_{\mathrm{CT}}$. Using bootstrap sampling, we compared the distributions of $Q_{\mathrm{CT}}$ and $F_{\mathrm{CT}}$. To generate a bootstrap sample from one of the species, we first randomly chose a population from that species. We then drew $n$ individuals randomly with replacement from those in that population, where $n$ was the actual number of individuals scored in that population. We continued sampling in this way until the number of populations in the sample was equal to the number actually scored. For each species, we preformed 1000 bootstrap samples.

For each bootstrap sample, we calculated $Q_{\mathrm{CT}}$ or $F_{\mathrm{CT}}$ from the variance components from a standard nested ANOVA. Because $V_{I}$ is the additive genetic variance within populations and could not be calculated for the traits from our data, we instead examined two extremes: heritability $=1$ and heritability $=0$. For heritability $=1, V_{I}$ was set equal to the within-population component of variation from the nested ANOVA for the trait (equal to the within-population phenotypic variance); for heritability = 0 , we set $V_{I}=0$. Because both approaches led to similar results, we report only the results for $V_{I}=$ within population variance component. This approach is conservative because it produces a smaller $Q_{\mathrm{CT}}$.

\section{RESULTS \\ SELFING RATES}

The eight populations of I. lacunosa we sampled uniformly exhibited very high selfing rates (mean $s=0.955 \pm 0.018$ Table 1). By contrast, $I$. cordatotriloba populations were more variable across populations [mean $s=0.511 \pm 0.182$ (negative estimates considered 0); Table 1]. This difference is statistically significant (one-tailed $t$-test: $t=2.43, d f=13, p<0.025$ ). It thus appears that selfing rate is on average substantially higher for I. lacunosa than for I. cordatotriloba.

Because in many plant species, variation in selfing rate is associated with variation in floral morphological characteristics, we examined the relationship between selfing rate and morphological variables corolla length and width, anther-stigma distance and style length and their squares for the combined data from the two species (Table 2). In a backward-elimination multiple regression involving these variables, all variables except antherstigma distance and the square of style length were eliminated from the regression. The regression involving these two variables explained $79 \%$ of the variation in selfing rate (Figure 2). Antherstigma distance and style length were both highly significant $\left[F_{(1,9)}=11.63\right.$ and $31.36, p<0.0077$ and 0.0003 , respectively $]$. Moreover, each of these variables differed significantly between the two species [Anther-stigma distance: $F_{(1,10)}=20.14, p=$ 0.0012; Square of style length: $\left.F_{(1,10)}=64.93, p<0.0001\right]$. It thus appears that much of the variation between species is due to the joint effects of these two morphological variables.

As remarked above, I. cordatotriloba populations are substantially variable for selfing rate. Among just these populations, 
Table 1 | Measures of genetic diversity and selfing rate for 7 populations of $I$. cordatotriloba and 8 populations of $I$. lacunosa from North Carolina and South Carolina.

\begin{tabular}{llllllr}
\hline Population & $\boldsymbol{N}$ & $\boldsymbol{N P L}$ & $\boldsymbol{A}$ & Ho & He & \multicolumn{1}{c}{$\boldsymbol{s}$} \\
\hline I. CORDATOTRILOBA & & & & & \\
cle1 & 18 & 2 & $2.0(0.0)$ & 0.03 & 0.33 & 0.95 \\
c7 & 13 & 4 & $3.0(1.4)$ & 0.61 & 0.55 & -0.24 \\
c13 & 23 & 2 & $2.5(0.7)$ & 0.04 & 0.27 & 0.92 \\
cl4 & 12 & 3 & $2.7(1.2)$ & 0.06 & 0.43 & 0.93 \\
c22 & 8 & 4 & $2.5(0.6)$ & 0.50 & 0.43 & -0.39 \\
c29 & 6 & 1 & $2.0(0.0)$ & 0.30 & 0.30 & 0.00 \\
clela3 & 17 & 2 & $2.0(0.0)$ & 0.18 & 0.50 & 0.78 \\
I. LACUNOSE & & & & & & \\
la3 & 14 & 1 & $2.0(0.0)$ & 0.00 & 0.50 & 1.00 \\
la15 & 14 & 2 & $4.0(0.0)$ & 0.04 & 0.37 & 0.94 \\
lela8 & 31 & 2 & $2.5(0.7)$ & 0.05 & 0.26 & 0.89 \\
la43 & 8 & 2 & $2.0(0.0)$ & 0.00 & 0.38 & 1.00 \\
la30 & 14 & 2 & $2.0(0.0)$ & 0.04 & 0.20 & 0.89 \\
la35 & 16 & 2 & $3.0(1.4)$ & 0.03 & 0.20 & 0.92 \\
la7 & 6 & 1 & $2.0(0.0)$ & 0.00 & 0.30 & 1.00 \\
ula7 & 6 & 1 & $3.0(0.0)$ & 0.00 & 0.55 & 1.00 \\
\hline
\end{tabular}

$N$, sample size; NPL, number of polymorphic loci; $A$, mean (sd) number of alleles; Ho, observed heterozygosity; He, expected heterozygosity; s, selfing rate.

a multiple regression of selfing rate on anther-stigma distance and the square of style length yielded a significant effect of the latter variable $\left[F_{(1,4)}=8.40, p=0.0442\right]$. The effect of antherstigma distance was not quite significant $\left[F_{(1,4)}=1.98, p=\right.$ 0.118 ], though this is perhaps not surprising given the small number of populations. Overall, the square of style length explains $52 \%$ of the variation in selfing rate among I. cordatotriloba populations and anther-stigma distance explains another $27 \%$. Moreover, the estimated regression coefficients are similar for $I$. cordatotriloba and the combined 2-species sample (anther-stigma distance: $0.72 \pm 0.361$ vs. $0.81 \pm 0.24$, respectively; square of style length: $-0.0070 \pm 0.0024$ vs. $-0.0053 \pm 0.00096$, respectively). It thus seems likely that, as for the overall difference in selfing rates between the two species, these variables also account for much of the variation in selfing rate among $I$. cordatotriloba populations.

\section{SELECTION ON DIVERGENT TRAITS}

To test whether divergence in floral morphological traits between $I$. cordatotriloba and I. lacunosa is consistent with neutral divergence, we conducted a hierarchal $Q_{\mathrm{CT}}-F_{\mathrm{CT}}$ analysis. If $Q_{\mathrm{CT}}>F_{\mathrm{CT}}$, divergence in the trait is typically inferred to be caused by selection. By contrast, if $Q_{\mathrm{CT}}=F_{\mathrm{CT}}$, then the data is consistent with divergence by genetic drift. We performed a comparison of $Q_{\mathrm{CT}}$ vs. $F_{\mathrm{CT}}$ for the measured floral traits, as well as for leaf traits that served as a control.

$Q_{\mathrm{CT}}$ values calculated for flower length, flower width, and flower length-width ratio are extremely differentiated from $F_{\mathrm{CT}}$ values (Figure 3). For flower length and width, the distribution of bootstrap values of $F_{\mathrm{CT}}$ does not overlap the distribution

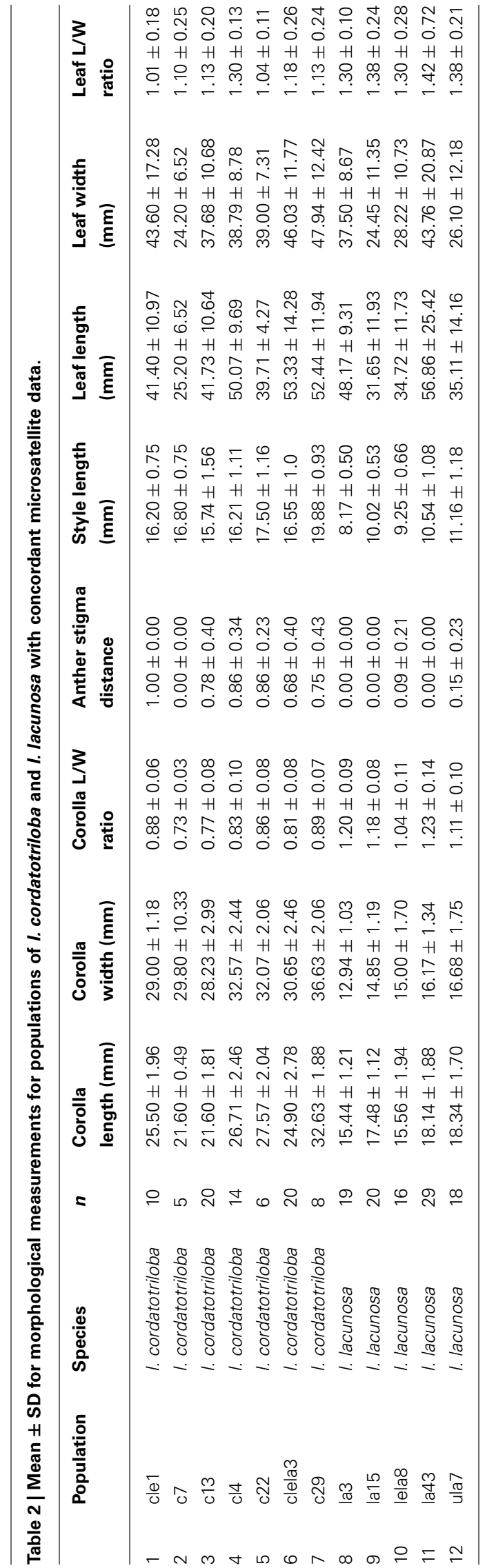




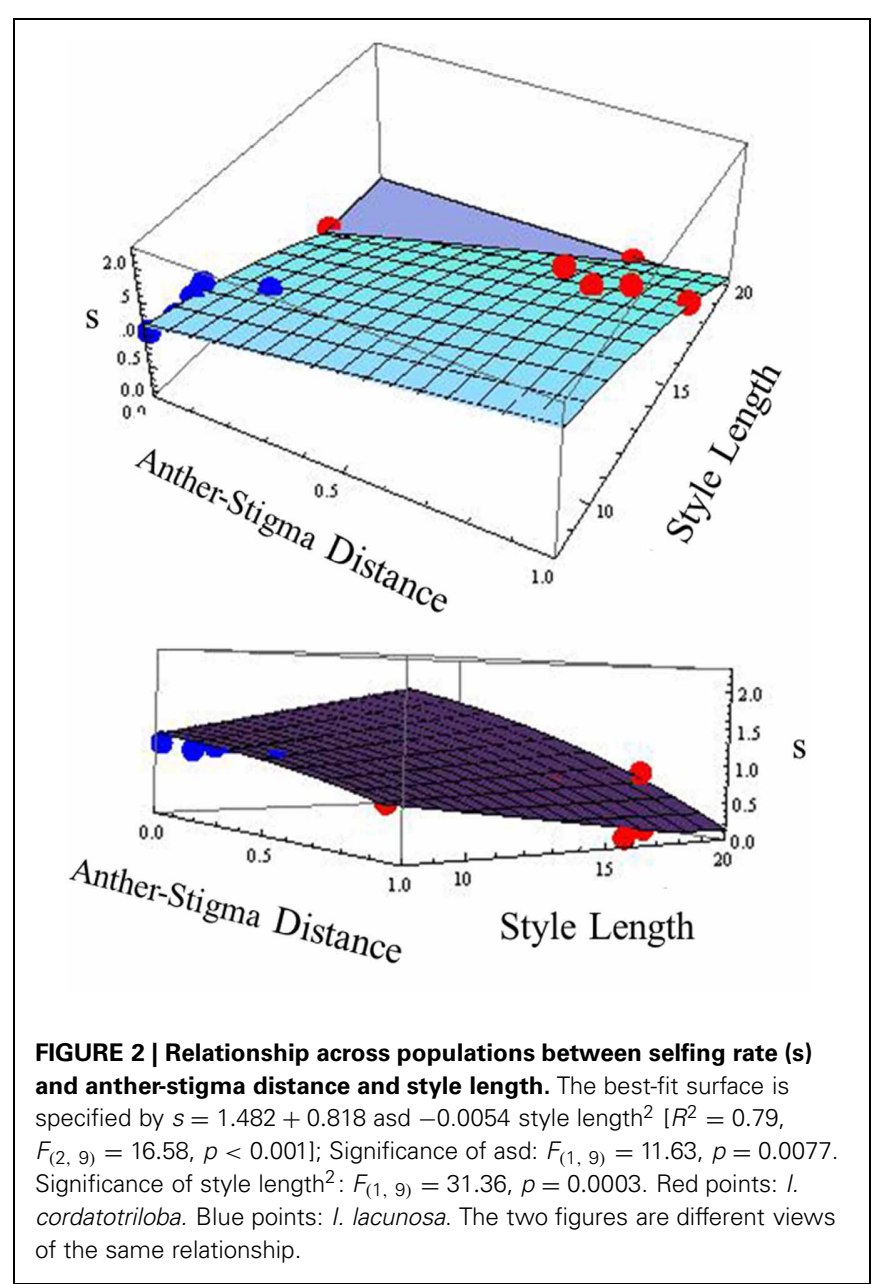

for $Q_{\mathrm{CT}}$, while for the ratio of floral length/width, there is only minimal overlap. In all three cases the significance of the difference is $p<0.001$, indicating divergence is inconsistent with neutral expectations. Because these traits are moderately correlated (Table 3 ), these tests may not be independent and divergence in these traits may reflect selection on a single, composite developmental character. Style length and anther-stigma distance are less correlated with corolla length and width and with each other than are corolla length and width to each other (Table 3 ). Thus, style length and antherstigma distance presumably represent separate developmental modules, while corolla length and width do not. However, for these characters there is little or no overlap between the bootstrap distributions of $Q_{\mathrm{CT}}$ and $F_{\mathrm{CT}}$ (Figure 4). Both of these differences are significant (style length, $p<0.001$; anther-stigma distance, $p=0.002$ ), again indicating inconsistency with neutral expectations.

By contrast with the floral characters, distributions of $Q_{\mathrm{CT}}$ and $F_{\mathrm{CT}}$ values broadly overlap for leaf length, leaf width, leaf lengthwidth ratio (Figure 5) and differences are not statistically significant (leaf length, $p=0.80$; leaf width, $p=0.64$; leaf length-width ratio, $p=0.44$ ). This pattern provides no evidence for selection causing divergence in these traits and indicates they are diverging neutrally.
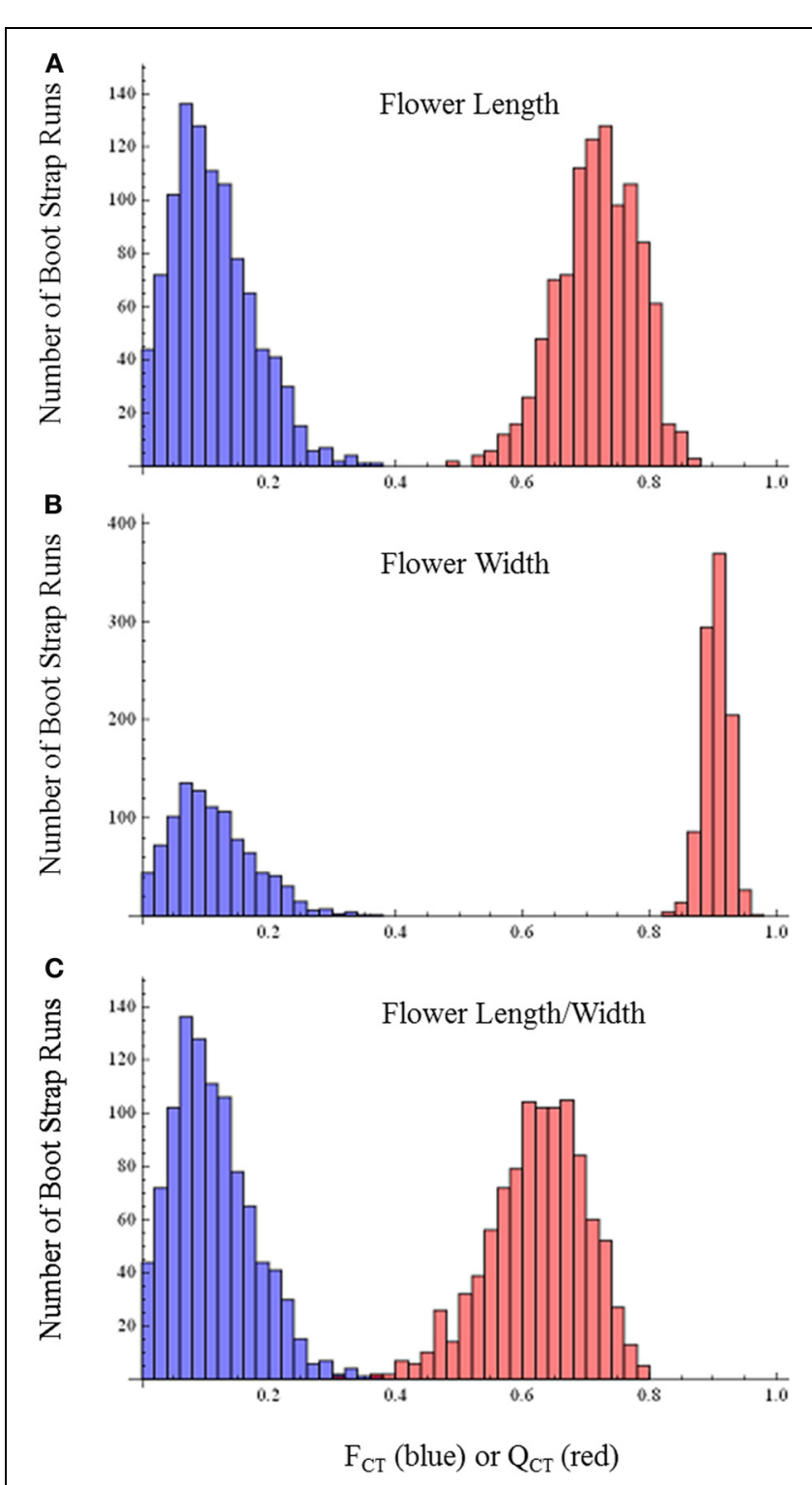

FIGURE $3 \mid F_{\mathrm{CT}}$ vs. $Q_{\mathrm{CT}}$ analyses (A) flower length $(p<0.001)$ (B) flower width $(p<0.001)$ (C) flower length-width ratio $(p<0.001)$.

\section{DISCUSSION}

\section{EVOLUTION OF SELFING RATES}

Our results verify that I. lacunosa is highly selfing whereas I. cordatotriloba appears to have a mixed mating system. This difference in selfing rates is explainable by reduced anther-stigma distance in I. lacunosa, which in other plant species increases autogamy (Chang and Rausher, 1998; Schueller, 2004; Takebayashi et al., 2006), as well as by a reduction in style length.

I. cordatotriloba populations are much more variable in estimated selfing rate than I. lacunosa populations. Some populations exhibit selfing rates nearly as high as those in I. lacunosa, whereas others are estimated to be largely outcrossing (Table 1). Although spatial variation in the availability of pollinators could conceivably contribute to this variation (Barrett et al., 1996), most of 
Table 3 | The average phenotypic correlations \pm standard error between pairs of measured traits within populations of $I$. cordatotriloba and $I$. lacunosa.

Corolla length Corolla width Corolla length/width Anther-stigma distance Style length Leaf length Leaf width

Corolla length

Corolla width

Corolla length/width

$0.36 \pm 0.23$

Anther-stigma distance

Style length

$0.56 \pm 0.20-0.43 \pm 0.36$

Leaf length

$-0.03 \pm 0.16$

$-0.03 \pm 0.29$

$0.20 \pm 0.33 \quad 0.28 \pm 0.25$

$-0.02 \pm 0.28$

$0.08 \pm 0.36$

$0.00 \pm 0.23$

Leaf width

$-0.04 \pm 0.32$

$0.17 \pm 0.28$

$0.04 \pm 0.33$

Leaf length/width

$-0.10 \pm 0.20$

$-0.05 \pm 0.36$

$-0.10 \pm 0.38$

$0.07 \pm 0.19$

$-0.15 \pm 0.23$

$0.08 \pm 0.28$

$-0.04 \pm 0.35$

$0.04 \pm 0.26$

$0.07 \pm 0.31$

$-0.10 \pm 0.44$

$0.79 \pm 0.22$

$0.00 \pm 0.23$

$0.12 \pm 0.36-0.06 \pm 0.38 \quad 0.43 \pm 0.43$

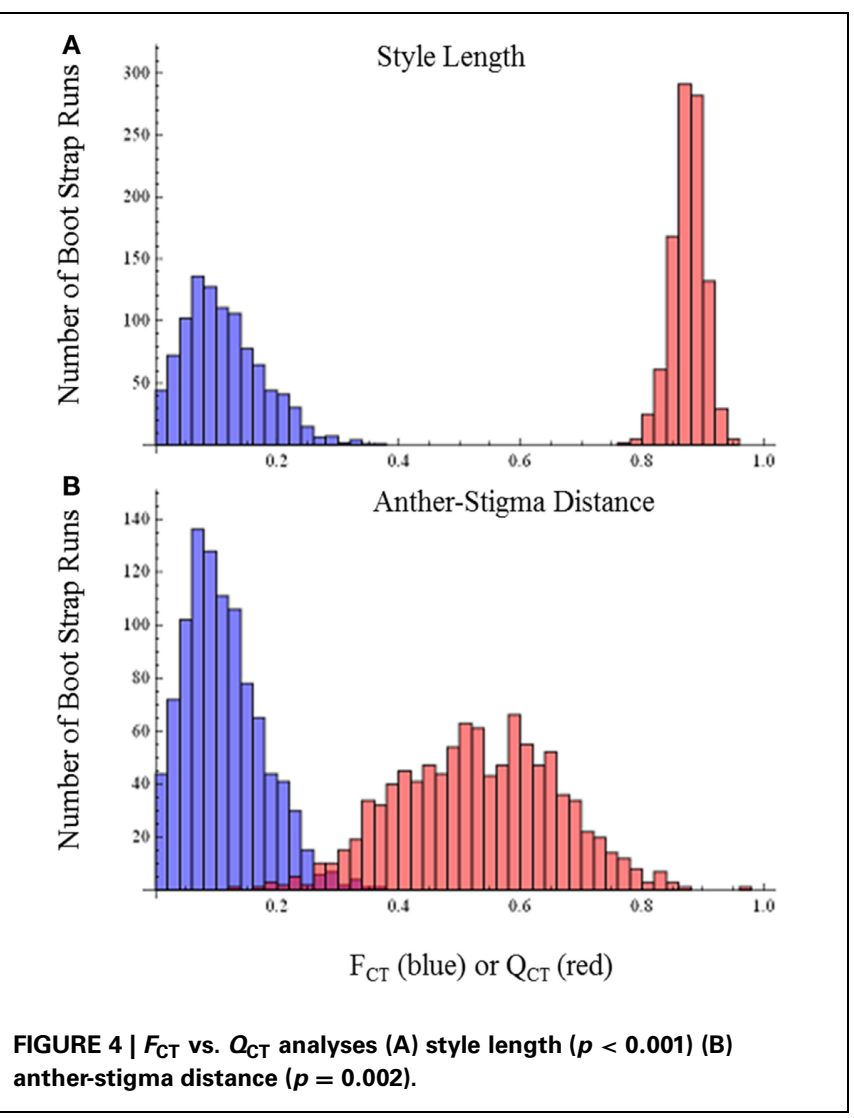

it appears to be explainable by variation in floral morphology. In particular, selfing rate seems to be determined largely by anther-stigma distance and style length. While reduced antherstigma distance typically increases selfing rates in plants (Motten and Stone, 2000), it is unclear how reduced style length contributes to increased selfing in the two Ipomoea species. The existence of between-population variation in these characters in $I$. cordatotriloba suggests that standing genetic variation in these characters may have facilitated even further reduction in anther-stigma distance and style length in I. lacunosa.

\section{SELECTION ON CATEGORY 1 TRAITS}

As described in the introduction, Category 1 traits are traits for which variation directly affects selfing rate and that are likely
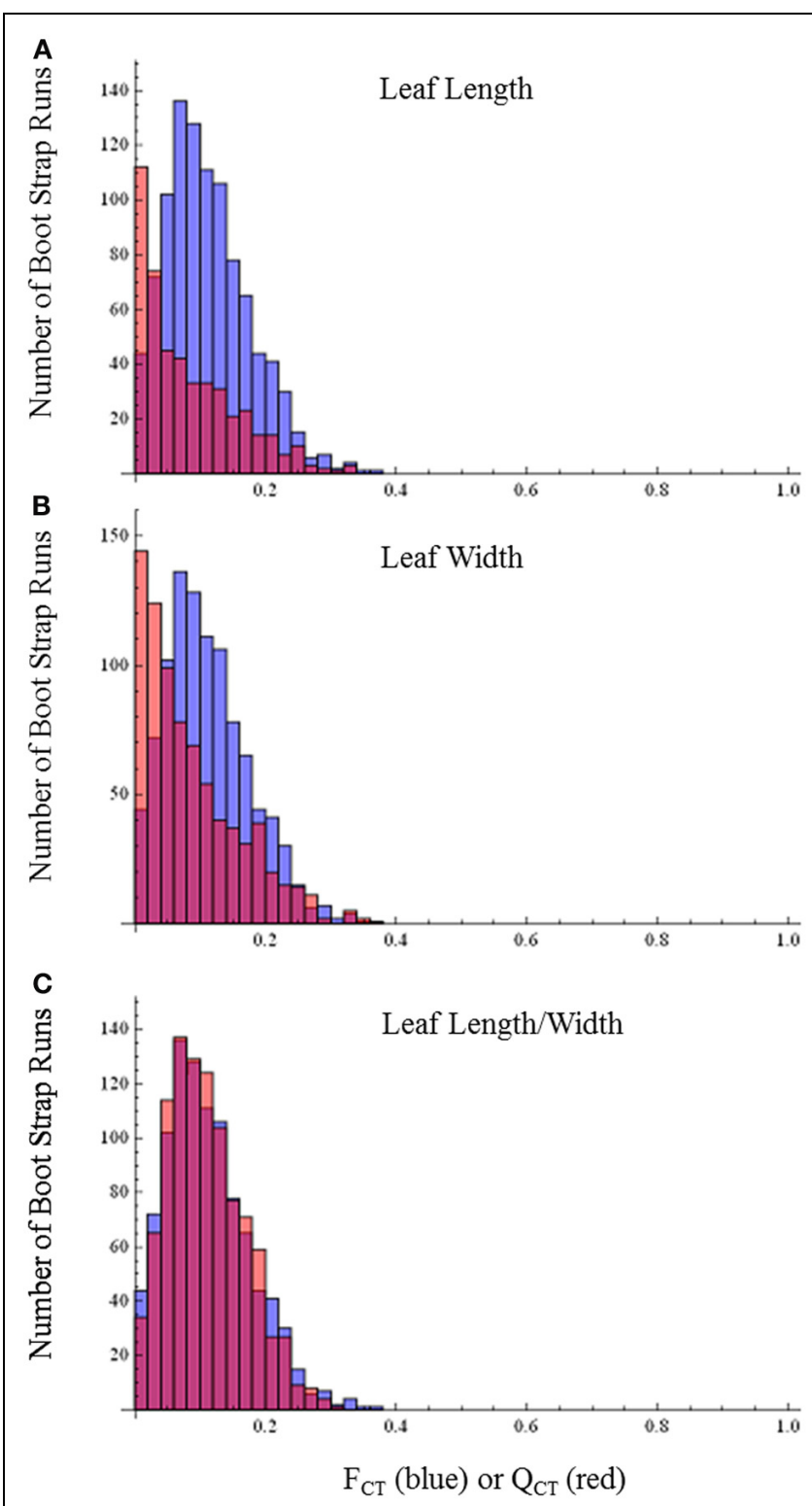

FIGURE 5 | $F_{\mathrm{CT}}$ vs. $Q_{\mathrm{CT}}$ analyses (A) leaf length $(p=0.80)$ (B) leaf width $(\boldsymbol{p}=\mathbf{0 . 6 4 )}(\mathrm{C})$ leaf length-width ratio $(\boldsymbol{p}=\mathbf{0 . 4 4})$. Orange bars indicate portion of red bar that does not overlap blue bar. 
targets of selection acting to alter selfing rate. Our analyses suggest that both anther-stigma distance and also style length are likely Category 1 traits. Both of these traits are highly correlated with selfing rates at the population level.

Our a priori expectation was that divergence in Category 1 traits would likely be caused by natural selection rather than genetic drift because it is difficult to imagine that variation in selfing rate would be selectively neutral. In order to be neutral, there would have to be precise tradeoffs among inbreeding depression, pollen discounting, and the benefits of reproductive assurance (Holsinger, 1988) that yielded no fitness differences among genotypes with different character values of these traits, which would require an improbable balance of effects. This expectation was in fact realized: both anther-stigma distance and style length exhibited a $Q_{\mathrm{CT}}$ between species that was substantially greater than $F_{\mathrm{CT}}$, indicating that divergence is inconsistent with neutral processes.

Although a number of advantages have been suggested for increased selfing, including pollinator uncertainty, avoidance of interspecific hybridization, and increased genetic transmission (Fisher, 1941; Smith and Rausher, 2007), we currently have no information that would allow us to distinguish among these possibilities. However, it is likely that the evolution of high levels of selfing set the stage for the subsequent evolution of other selfing-syndrome characters.

\section{SELECTION ON OTHER TRAITS}

Our results indicate that divergence between I. lacunosa and $I$. cordatotriloba in floral size was driven by natural selection. One possible explanation for this divergence is that it is the result of indirect selection due to correlations between anther-stigma distance and corolla dimensions and selection on the former. We believe, however, that this explanation is unlikely. Although we did not measure genetic correlations among these traits, the phenotypic correlations between anther-stigma distance and corolla

\section{REFERENCES}

Abel, W. E., and Austin, D. F. (1981). Introgressive hybridization between Ipomoea trichocarpa and Ipomoea lacunosa (Convolvulaceae). Bull. Torrey Bot. Club 108, 231-239. doi: 10.2307/2484902

Ashman, T. L., and Majetic, C. J. (2006). Genetic constraints on floral evolution: a review and evaluation of patterns. Heredity 96, 343-352. doi: 10.1038/sj.hdy. 6800815

Austin, D. F. (1978). Ipomoea-batatas complex. 1. taxonomy. Bull. Torrey Bot. Club 105, 114-129. doi: $10.2307 / 2484429$

Baker, H. G. (1955). Self-compatibility and establishment after "longdistance" dispersal. Evolution 9, 347-348. doi: 10.2307/2405656

Barrett, S. C. H. (2002). The evolution of plant sexual diversity. Nat. Rev. Genet. 3, 274-284. doi: $10.1038 /$ nrg776
Barrett, S. C. H., Emerson, B., and Mallet, J. (1996). The reproductive biology and genetics of island plants [and discussion]. Philos. Trans. Biol. Sci. 351, 725-733. doi: 10.1098/rstb.1996.0067

Brunet, J. (1992). Sex allocation in hermaphroditic plants. Trends Ecol. Evol. 7, 79-84. doi: 10.1016/01695347(92)90245-7

Chang, S. M., and Rausher, M. D. (1998). Frequency-dependent pollen discounting contributes to maintenance of a mixed mating system in the common morning glory Ipomoea purpurea. Am. Nat. 152, 671-683. doi: 10.1086/286198

Charlesworth, D., and Wright, S. I. (2001). Breeding systems and genome evolution. Curr. Opin. Genet. Dev. 11, 685-690. doi: 10.1016/S0959-437X(00)00254-9

Darwin, C. (1876). The Effects of Cross and Self-Fertilisation in the Vegetable Kingdom. London: John Murray.

dimensions are very low and not significantly different from 0 . We suspect these reflect underlying low genetic correlations that would essentially preclude the evolution of reduced corollas due to indirect selection.

It also seems unlikely that direct selection to reduce selfing rates acted to reduce corolla size in I. lacunosa. Because variation in anther-stigma distance and style length accounts for approximately $80 \%$ of the variation in selfing rates, while corolla dimensions are not significantly related to selfing rate, there is little scope for this type of selection. Instead, we suspect that reduction in corolla size in I. lacunosa resulted from selection to redirect resources from petals to other fitness-enhancing traits (Brunet, 1992). Final resolution of this issue, however, must await functional analysis of selection on these traits.

\section{SELECTION ON VEGETATIVE TRAITS}

Even though floral size and mating systems have been found to be extremely correlated, a systematic survey of outcrossing and selfing species found that there is a much weaker correlation between flower size and vegetative tissue dimensions, such as leaf length or width (Ashman and Majetic, 2006). We also found very weak phenotypic correlations between floral traits and leaf size, suggesting that evolution of leaf traits should not be influenced by indirect selection on floral traits. Our results are consistent with this expectation. In particular, we found no significant differences between $F_{\mathrm{CT}}$ and $Q_{\mathrm{CT}}$ for leaf dimensions, indicating that divergence in leaf traits are primarily due to genetic drift. Thus, as has been found in other systems (Ashman and Majetic, 2006), evolution of leaf size appears to be independent of the evolution of floral characters.

\section{ACKNOWLEDGMENTS}

This work was supported by a National Science Foundation grant to Mark D. Rausher.

Doyle, J. J., and Doyle, J. L. (1981). A rapid DNA isolation procedure for small quantities of fresh leaf tissue. Phytochem. Bull. 19, 11-15.

Duncan, T. M. (2013). The Mating System Evolution of Ipomoea lacunosa. Ph.D. thesis, Duke University, Durham, USA.

Duncan, T. M. (in press). Morphological and genetic differentiation and reproductive isolation among closely related taxa in the Ipomoea series Batatas. Am. J. Bot.

Excoffier, L., and Lischer, H. E. L. (2010). Arlequin suite ver 3.5: a new series of programs to perform population genetics analyses under linux and windows. Mol. Ecol. Resour. 10, 564-567. doi: $\quad 10.1111 /$ j.1755-0998.2010. 02847.x

Fisher, R. A. (1941). Average excess and average effect of a gene substitution. Ann. Eugen. 11,
53-63. doi: 10.1111/j.14691809.1941.tb02272.x

Hartl, D. L., and Clark, A. G. (1997). Principles of Population Genetics. Sunderland, MA: Sinauer Associates, Inc.

Holsinger, K. E. (1988). Inbreeding depression doesn't matter: the genetic basis of mating system evolution. Evolution 42, 1235-1244. doi: 10.2307/2409007

Hu, J., Nakatani, M., Lalusin, A. G., and Fujimura, T. (2004). New microsatellite markers developed from reported Ipomoea trifida sequences and their application to sweetpotato and its related wild species. Scientia Horticulturae 102, 375-386. doi: 10.1016/j.scienta.2004.04.014

Jones, A., and Deonier, M. T. (1965). Interspecific crosses among Ipomoea lacunosa, I. ramoni, I. trichocarpa and I. triloba. Bot. Gaz. 126, 226-232. doi: 10.1086/336326 
Kalisz, S., Randle, A., Chaiffetz, D., Faigeles, M., Butera, A., and Beight, C. (2012). Dichogamy correlates with outcrossing rate and defines the selfing syndrome in the mixed-mating genus Collinsia. Ann. Bot.109, 571-582. doi: 10.1093/aob/mcr237

Leinonen, T., O’hara, R. B., Cano, J. M., and Merila, J. (2008). Comparative studies of quantitative trait and neutral marker divergence: a meta-analysis. J. Evol. Biol. 21, 1-17.

McDonald, A. J., Hansen, D. R., McDill, J. R., and Simpson, B. B. (2011). A phylogenetic assessment of breeding systems and floral morphology of north american Ipomoea (Convolvulacea). J. Bot. Res. Inst. Texas 5, 159-177.

Motten, A. F., and Stone, J. L. (2000). Heritability of stigma position and the effect of stigma-anther separation on outcrossing in a predominantly self-fertilizing weed, Datura stramonium (Solanaceae).
Am. J. Bot. 87, 339-347. doi: $10.2307 / 2656629$

Ornduff, R. (1969). Reproductive biology in relation to angiosperm systematics. Taxon 18, 121-133. doi: $10.2307 / 1218671$

Pollak, E. (1987). On the theory of partially inbreeding finite populations. I. partial selfing. Genetics 117, 353-360.

Schueller, S. K. (2004). Self-Pollination in island and mainland populations of the introduced hummingbird-pollinated plant, Nicotiana glauca (Solanaceae). Am. J. Bot. 91, 672-681. doi: 10.3732/ajb. 91.5.672

Sicard, A., and Lenhard, M. (2011). The selfing syndrome: a model for studying the genetic and evolutionary basis of morphological adaptation in plants. Ann. Bot. 107, 1433-1443. doi: 10.1093/aob/mcr023

Smith, R. A., and Rausher, M. D. (2007). Close clustering of anthers and stigma in Ipomoea hederacea enhances prezygotic isolation from
Ipomoea purpurea. New Phytol. 173, 641-647. doi: 10.1111/j.1469-8137. 2006.01933.x

Stebbins, G. L. (1950). Variation and the Evolution of Plants. New York, NY: Columbia University Press.

Takebayashi, N., Wolf, D. E., and Delph, L. F. (2006). Effect of variation in herkogamy on outcrossing within a population of Gilia achilleifolia. Heredity (Edinb) 96, 159-165. doi: 10.1038/sj.hdy. 6800780

Whitlock, M. C. (2008). Evolutionary inference from Q(ST). Mol. Ecol. 17, 1885-1896. doi: 10.1111/j.1365294X.2008.03712.x

Whitlock, M. C., and Gilbert, K. J. (2012). QST in a hierarchically structured population. Mol. Ecol. Resour. 12, 481-483. doi: $\quad 10.1111 /$ j.1755-0998.2012. 03122.x

Conflict of Interest Statement: The authors declare that the research was conducted in the absence of any commercial or financial relationships that could be construed as a potential conflict of interest.

Received: 30 April 2013; paper pending published: 13 June 2013; accepted: 20 July 2013; published online: 09 August 2013.

Citation: Duncan TM and Rausher MD (2013) Evolution of the selfing syndrome in Ipomoea. Front. Plant Sci. 4:301. doi: 10.3389/fpls.2013.00301

This article was submitted to Frontiers in Plant Evolution and Development, a specialty of Frontiers in Plant Science.

Copyright (c) 2013 Duncan and Rausher. This is an open-access article distributed under the terms of the Creative Commons Attribution License (CC BY). The use, distribution or reproduction in other forums is permitted, provided the original author(s) or licensor are credited and that the original publication in this journal is cited, in accordance with accepted academic practice. No use, distribution or reproduction is permitted which does not comply with these terms. 